\title{
Differential Specificity of Interferon-alpha Inducible Gene Expression in Association with Human Immunodeficiency Virus and Hepatitis C Virus Levels and Declines in vivo
}

\author{
Antonios Katsounas ${ }^{1,2, *}$, Astrid C Frank ${ }^{2}$, Richard A Lempicki ${ }^{3}$, Michael A Polis ${ }^{2}$, David M Asmuth ${ }^{4}$ and Shyam Kottilil ${ }^{2}$ \\ ${ }^{1}$ Department of Gastroenterology and Hepatology, University Hospital Essen, Hufelandstrasse 55, 45147 Essen, Germany \\ ${ }^{2}$ Laboratory of Immunoregulation, National Institute of Allergy and Infectious Diseases, National Institutes of Health, 10 Center Dr., Bethesda, MD 20892, USA \\ ${ }^{3}$ Leidos Biomedical Research Inc., Frederick National Laboratory for Cancer Research, Frederick, MD, USA \\ ${ }^{4}$ Division of Infectious and Immunologic Diseases, UC Davis, Medical Center 4150 V Street, PSSB G500 Sacramento, CA 95817, USA
}

\begin{abstract}
Objective: This study was aimed to correlate in vivo interferon (IFN) inducible gene (IFIG) expression and IFIG induction with viral-load (VL) and VL-kinetics of Human-Immunodeficiency-Virus (HIV) or Hepatitis-C-Virus (HCV) in HIV-positive patients treated with pegylated IFN-alpha-2a (PegIFNa).

Methods: HIV mono-infected patients $(\mathrm{N}=8)$ and HIV/HCV co-infected patients ( $\mathrm{N}=23$, without HIV-viremia) were treated with PegIFNa (180 $\mu \mathrm{g} /$ week) for 12 and 48 weeks, respectively. Blood sampling for monitoring IFIG expression occurred at day_0 and week_3, 6 and_12 for HIV mono-infected patients vs. only at day_0 and week_48 for HIV/ $\mathrm{HCV}$ co-infected subjects. IFIG expression $(\mathrm{N}=20)$ was measured in peripheral blood mononuclear cells by bDNAassay. VL levels/changes in plasma were analyzed for correlation with IFIG expression/induction at/between selected time points. Overall, $\mathrm{P}<0.05$ was considered significant.
\end{abstract}

Results: None of the 20 IFIG expression profiles at day 0 correlated significantly with HIV-VL at day 0 . Expression at day_0 of 3 IFIG (APOBEC3G/OAS1/OAS2) correlated significantly $(r>+0.42 / P<0.05)$ with HCV-VL at day_0. The strongest antiviral effect [measured as median viral decline per week: $\Delta V L /$ week (log10)] occurred in common against HIV and HCV between day_0 and week_3 during 12 weeks of continuous PegIFNa treatment in both cohorts. Expression at day 0 of 1 IFIG (APOBEC3A) correlated significantly $(r<-0.71 / P<0.05)$ with HIV- $\Delta$ VL/week $(\log 10)$ from day_0 to week_3. No significance was reached in correlations between expression values of 20 IFIG at day_0 and HCV- $\Delta$ VL/week (log10) from day 0 to week 3. No significant correlation was detected between IFIG expression changes $(\Delta \mathrm{IFIG}=$ induction) from day_0 to week_3 and HIV- $\Delta \mathrm{VL} /$ week (log10) from day_0 to week_3. Interestingly, induction of 1 IFIG $(\triangle I S G 20)$ from day_0 to week_48 was significantly associated $(P<0.05)$ with permanent $\mathrm{HCV}$ clearance.

Conclusion: This study demonstrates the differential specificity of PegIFNa mediated molecular actions by dissecting the kinetics of IFIG expression and induction, suggesting multiple, possibly non-overlapping mechanisms for antiviral effects against HCV and HIV.

Keywords: Hepatitis C; Human Immunodeficiency Virus; Interferon inducible genes; Viral kinetics

Abbreviations: APOBEC: Apolipoprotein B mRNA-editing enzyme; ART: Antiretroviral Therapy; DAA: Direct Acting Antivirals; EIF2AK2: Eukaryotic Translation Initiation Factor 2-alpha kinase 2; G1P3: Interferon Stimulated Gene 6-16; HCV: Hepatitis C Virus; HIV: Human Immunodeficiency Virus; IFI: Interferon Inducible Protein; IFIG: Interferon Inducible Gene; IFIT: Interferon Induced Protein with Tetratricopeptide Repeats; IFITM: Interferon Induced Transmembrane; IFN: Interferon; ISG: Interferon Stimulated Gene; MX: Myxovirus Resistance; OAS: 2',5' oligoadenylate synthetase; PBMC: Peripheral Blood Mononuclear Cell; PegIFNa: Pegylated IFN-alpha; PLSCR1: Phospholipid Scramblase 1; STAT1: Signal Transducer and Activator of Transcription 1; SVR: Sustained Viral Response, TRIM: Tripartite Motif; VL: Viral Load

\section{Objective}

Interferons (IFN) play a major role in innate antiviral immunity and have been used in the treatment of diseases caused by various RNA viruses [1]. In the past, IFN has been given in clinical trials as anti-Human Immunodeficiency Virus (HIV) medication with poor sustained efficacy (reviewed in [2]) and current HIV treatment does not involve immunomodulatory therapeutics. Although antiretroviral therapy (ART) has been shown to reduce morbidity and mortality in HIV infected subjects worldwide, it cannot eradicate HIV infection. On the other hand, IFN have been proven to cure chronic viral diseases, as in the case of Hepatitis B Virus (HBV) [3] and Hepatitis C Virus (HCV) [4]. In HCV positive patients, IFN based therapy has demonstrated variable success in eradicating HCV infection (reviewed in [5]) and in vitro studies have suggested possible IFN effects in suppressing both HCV and HIV replication [6]. Furthermore, recent in vitro studies

*Corresponding author: Antonios Katsounas, Department of Gastroenterology and Hepatology, University Hospital Essen, Hufelandstrasse 55, 45147 Essen, Germany and Laboratory of Immunoregulation, National Institute of Allergy and Infectious Diseases, National Institutes of Health, 10 Center Dr., Bethesda, MD 20892, USA, Tel: 0049-201-723-83407; Fax: 0049-208-847-09952; E-mail antonios.katsounas@uk-essen.de

Received October 18, 2014; Accepted December 22, 2014; Published January 02, 2015

Citation: Katsounas A, Frank AC, Lempicki RA, Polis MA, Asmuth DM, et al. (2015) Differential Specificity of Interferon-alpha Inducible Gene Expression in Association with Human Immunodeficiency Virus and Hepatitis $C$ Virus Levels and Declines in vivo. J AIDS Clin Res 6: 410. doi:10.4172/2155-6113.1000410

Copyright: (c) 2015 Katsounas A, et al. This is an open-access article distributed under the terms of the Creative Commons Attribution License, which permits unrestricted use, distribution, and reproduction in any medium, provided the original author and source are credited. 
Citation: Katsounas A, Frank AC, Lempicki RA, Polis MA, Asmuth DM, et al. (2015) Differential Specificity of Interferon-alpha Inducible Gene Expression in Association with Human Immunodeficiency Virus and Hepatitis C Virus Levels and Declines in vivo. J AIDS Clin Res 6: 410. doi:10.4172/2155-6113.1000410

Page 2 of 6

have demonstrated that IFN dependent up-regulation of certain gene products, such as 2,5'-oligoadenylate synthetase (OAS) and myxovirus resistance 1 (MX1), executes antiviral activity [7-12]. While these genes are known to be important in suppressing HIV and HCV [13], in vivo evidence supporting the role of these genes is lacking.

Pegylated IFN-alpha-2a or -2b (PegIFNa) is an immunomodulatory agent approved by the Food and Drug Administration for therapeutic use against $\mathrm{HCV}$ and/or HBV infection. In in the era of Direct-acting Antivirals (DAA) that offer a viable IFN-free regimen for Hepatitis C, PegIFNa remains a still broadly used and cost-effective drug component of infection management. Several studies have shown that the antiviral activity of PegIFNa in suppressing HIV replication may involve preventing virion production, largely by inducing "apolipoprotein $\mathrm{B}$ mRNA editing enzyme, catalytic polypeptide-like" (APOBEC) proteins, whereas viral kinetic modeling suggests PegIFNa blocks de novo HIV infection of cells [14]. The parent study (AIDS Clinical Trials Group [ACTG] protocol 5192) of this work, a phase II PegIFNa trial in HIV mono-infected ART-naive patients, found that PegIFNa significantly decreased HIV viral load (VL), which correlated inversely with expression changes of OAS and other IFN inducible genes (IFIG) [15]. Decreased HIV-VL, however, did not correlate with serum interferon levels, nor prevented declines of $\mathrm{CD} 4^{+} \mathrm{T}$-cell counts [15].

The pharmacokinetic and pharmacodynamic profiles of PegIFNa for clinical and antiviral parameters were previously reported for HIV infected patients [15]. The objective of the current study was to characterize the IFN inducible host genetic response that is specifically responsible for anti-HIV and anti-HCV action in vivo. Therefore, using peripheral blood mononuclear cells (PBMC) from patients who were either HCV/HIV co-infected (HIV-aviremic) or HIV mono-infected and treated with PegIFNa $[15,16]$, we examined the expression profiles of IFIG to identify the most important differential associations of host response to therapeutic doses of PegIFNa with HIV-VL and HCV-VL levels and declines.

\section{Methodology}

\section{Study subjects}

At $\geq 2$ different time points, PBMC were obtained from 31 subjects recruited from two different cohorts $[15,16]$ and assigned to two clinical groups, i.e. HCV/HIV co-infected and HIV-aviremic patients (HCV genotype 1; $\mathrm{N}=23$ ) vs. HIV mono-infected and HIV-viremic patients $(\mathrm{N}=8)$. In $\mathrm{HCV}$-positive patients PBMC sampling occurred before (i.e. day_0) and at the end of a standard therapy over 48 weeks with PegIFNa-2b (1.5 $\mu \mathrm{g} / \mathrm{kg} /$ week; Peg-Intron; Schering-Plough) or PegIFNa-2a (180 $\mu \mathrm{g} /$ week; Pegasys; Roche) and ribavirin ((1000-1200 $\mathrm{mg} /$ day; Rebetol, Schering-Plough) as reported elsewhere [16]. In HIV mono-infected patients (drug-naïve or $\geq 12$ weeks from receiving ART) PBMC sampling occurred at day_0, week_3, week_6 and week_12 as previously described [15]. HIV mono-infected patients received PegIFNa-2a subcutaneously ( $180 \mu \mathrm{g} /$ week) in the clinic for 12 weeks with two scheduled follow-up visits at 1 and 6 weeks after the treatment period [15]. Safety parameters were frequently monitored in addition to HCV-VL or HIV-VL along with $\mathrm{CD}^{+} \mathrm{T}$-cell counts. To this end, peripheral blood samples were obtained from all study participants at least before initiation of treatment (i.e. day_0), at week_3, week_6, week_12 and the follow-up visits. (HCV-positive patients had more frequent routine lab tests according to standard treatment protocol). All subjects signed informed consents approved by the Institutional Review Board (IRB) of the National Institute of Allergy and Infectious Diseases (Bethesda, MD), and the study received official approval by the AIDS
Clinical Trials Group [ACTG protocol 5192] New Work Concept Sheet (NWCS 283) [15].

\section{Isolation of PBMC and RNA}

PBMC were isolated from white blood cells by the standard FicollHypaque Plus (Amersham Biosciences, Uppsala, Sweden) density gradient separation technique. RNA was isolated via Qiagen mRNA kits (Qiagen, Germantown, MD) according to the manufacturer's protocol.

\section{bDNA multiplex assay}

The QuantiGene Plex 2.0 Assay (Panomics, Fremont, CA), a bDNA multiplex assay capable of simultaneously detecting the expression of 3 up to 36 RNA targets (http://www.panomics.com/index. php?id=products luminexAssays), was used for quantification of gene expression data as described elsewhere [17].

\section{HCV and HIV viral kinetics}

HCV-VL (log10, in $23 \mathrm{HCV} / \mathrm{HIV}$ co-infected patients) or HIVVL ( $\log 10$, in 8 HIV mono-infected patients) levels were measured at day_0, week_3, week_6 and week_12 and median per week viral declines (median $\Delta \mathrm{VL} /$ week, $\log 10$ ) were calculated between selected time points.

\section{Statistical analysis}

Given the differences resulting from distinct biological properties of HIV and HCV and the diversity of cells/organs that they infect, this study has been automatically confronted with the methodological difficulty of utilizing data with asymmetric structure and unbalanced power regarding the ability of analysis results to equally capture viral/ immunological aspects of HIV and/or HCV infection.

In a first step, linear regression analysis was performed (PARTEK Genomic Suite) between expression levels of 20 IFIG at baseline (i.e. day_0) and HCV-VL $(\log 10)$ or HIV-VL $(\log 10)$ at day_0 in HCV/HIV co-infected or HIV mono-infected patients, respectively.

In a second step, we sought to determine whether expression levels of 20 IFIG at baseline (i.e. day_0) correlated with viral drops of HCV or HIV during treatment with PegIFNa. To this end, median viral declines per week (median $\Delta \mathrm{VL} /$ week, $\log 10$ ) were calculated between day_0, week_3, week_6 and week_12 for HCV and HIV, in separate. As the strongest median per week VL declines $(\Delta \mathrm{VL} /$ week, $\log 10)$ occurred from day_0 to week_3 for both viruses (i.e. HCV and HIV) and HIVVL did not change significantly from week_3 (over week_6) to week_12 during PegIFNa therapy, we exclusively considered median $\Delta \mathrm{VL}$ /week between day_0 and week_3 for investigating VL levels/kinetics of both viruses in conjunction with host responses in our analyses. Overall, only those results have been presented that remained significant after accounting for False Discovery Rate (FDR, please read below).

While SVR is considered a clearly defined end point of PegIFNa based therapy against HCV, HIV-VL is a clinically important surrogate end point for HIV disease, which, however, cannot fully account for successful treatment outcome. To date, no therapy eradicates HIV; thus, in this study, no clear therapy end point could be defined for comparing HIV and HCV-infection at the level of sustained response to PegIFNa based treatment. Therefore, the third step of our analysis was de facto limited to implementation of linear regression analysis between treatment response and IFIG induction between baseline (i.e. day_0) and end of PegIFNa based therapy (i.e. week_48) in $23 \mathrm{HCV} / \mathrm{HIV}$ coinfected patients only. 
Citation: Katsounas A, Frank AC, Lempicki RA, Polis MA, Asmuth DM, et al. (2015) Differential Specificity of Interferon-alpha Inducible Gene Expression in Association with Human Immunodeficiency Virus and Hepatitis C Virus Levels and Declines in vivo. J AIDS Clin Res 6: 410. doi:10.4172/2155-6113.1000410

Page 3 of 6

In contrast to the HCV/HIV co-infected cohort [16], blood sampling for IFIG expression levels measurement was foreseen by study protocol for HIV mono-infected patients [15] not only at baseline (i.e. day_0) and the end of treatment (i.e. week_12) but also at week_3 and week_6. Here, we refrained from examining correlations of IFIG induction between day_0, week_3, week_6 and week_12 with HIVVL decline primarily because findings would not allow any clues to be drawn concerning the differential specificity of IFIG expression in association with HIV vs. HCV kinetics in vivo (which was a major aim of this study). Overall, we computed the Pearson correlation value $(r)$ along with the calculated $\mathrm{p}$ value $(\mathrm{P})$ for each contrast and then ranked all IFIG according to their $P$ values. The cutoff for statistical significance was set at $5 \%(\mathrm{P}<0.05)$. Overall, three different methods have been utilized to address FDR: the classical one-stage method [18], the twostage sharpened method [19] and the graphically sharpened method [20].

\section{Results}

As the strongest median per week VL declines $(\Delta \mathrm{VL} /$ week, $\log 10$ ) occurred from day_0 to week_3 for both viruses (i.e. HCV and HIV) and HIV-VL did not change significantly from week_3 (over week_6) to week_12 during PegIFNa therapy (Figure 1), we exclusively considered median $\Delta \mathrm{VL} /$ week between day_0 and week_3 for investigating VL levels/kinetics of both viruses in conjunction with host responses in our analyses. Overall, only those results have been presented that remained significant after accounting for False Discovery Rate (FDR, for more details please read under Methods/Statistical Analysis).

Differential association of IFIG expression levels at baseline (day_0) with HCV-VL vs. HIV-VL before initiation of PegIFNa therapy (day_0)

Linear regression analysis revealed a significant correlation $(\mathrm{r} \geq+0.42$ / $\mathrm{P}<0.05)$ between HCV-VL and expression levels of OAS1, OAS2, and APOBEC3G in HIV/HCV infected (HIV-aviremic) patients (after accounting for FDR, Figure 2). In contrast, none of the 20 IFIG expression profiles at day_0 correlated significantly with HIV-VL at day_0 (after accounting for FDR, Figure 2).
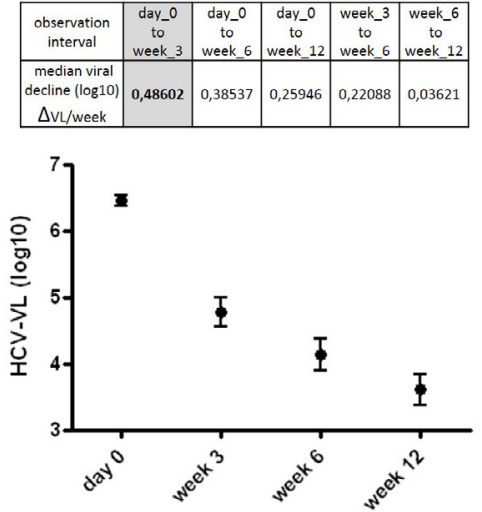

HCV/HIV co-infected patients, $\mathrm{N}=23$ (HIV-aviremic)
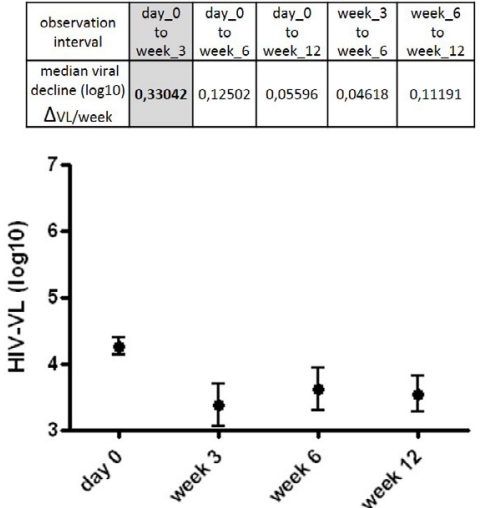

HIV mono-infected patients, $\mathrm{N}=8$

Figure 1: Viral load (VL) declines of the Hepatitis C Virus (HCV) and Human Immunodeficiency Virus (HIV).

Median viral load (VL) declines per week (median $\triangle \mathrm{VL} /$ week, log10) were calculated between day_0, week_3, week_6 and week_12 for HCV and HIV, in separate. The strongest (PegIFNa induced) median VL declines per week occurred from day_0 to week_ 3 for both viruses. $\Delta$ is the mathematical symbol for decline.

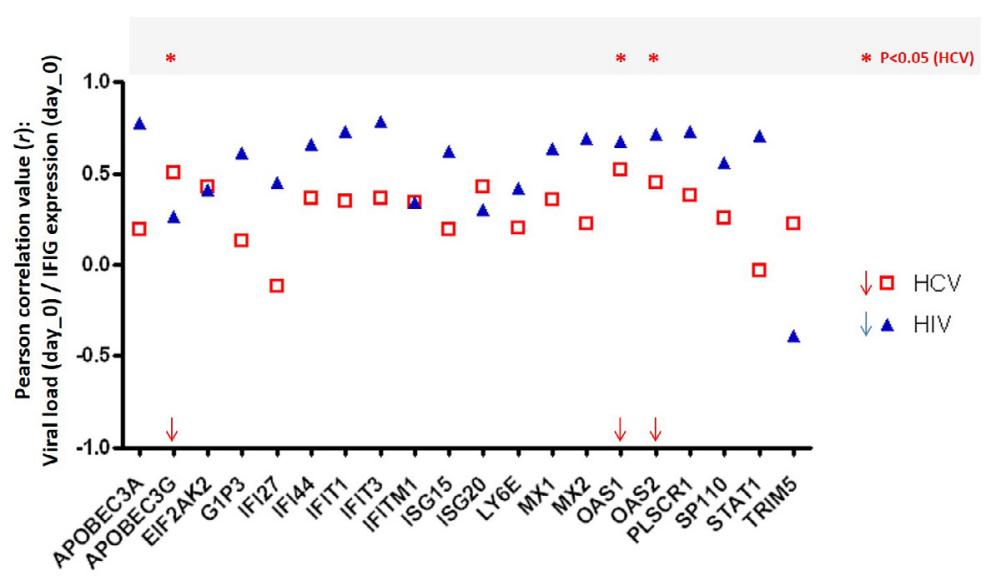

Figure 2: Correlation between Interferon inducible gene (IFIG) expression and viral load (VL) levels at baseline.

Differential association of IFIG expression levels (day 0) with Hepatitis C Virus (HCV)-VL and Human Immunodeficiency Virus (HIV)-VL before administration of pegylated interferon alpha (PegIFNa). Gene Symbols correspond to Entrez Gene IDs (http://www.ncbi.nlm.nih.gov/gene). 
Citation: Katsounas A, Frank AC, Lempicki RA, Polis MA, Asmuth DM, et al. (2015) Differential Specificity of Interferon-alpha Inducible Gene Expression in Association with Human Immunodeficiency Virus and Hepatitis C Virus Levels and Declines in vivo. J AIDS Clin Res 6: 410. doi:10.4172/2155-6113.1000410

Page 4 of 6

Differential association of IFIG expression levels at baseline (day_0) with HCV-VL and HIV-VL kinetics during PegIFNa therapy (day_0 to week_3)

No significant correlations were detected between IFIG expression and HCV-VL declines in $23 \mathrm{HIV} / \mathrm{HCV}$ co-infected (HIV-aviremic) patients (Figure 3). In $8 \mathrm{HIV}$ mono-infected patients, only baseline expression of APOBEC3A correlated significantly $(\mathrm{r} \leq-0.71 / \mathrm{P}<0.05)$ with HIV-VL decline (after accounting for FDR, Figure 3). Interestingly, a strong lack of PegIFNa driven induction of APOBEC3A has been observed in association with high vs. low HIV viremia at baseline; for visualizing this trend patients have been assigned in two groups depending on whether their HIV-VL at baseline (day_0) were below $(\mathrm{N}=3)$ or above $(\mathrm{N}=5)$ the median HIV-VL at baseline (day_0) as calculated for all HIV mono-infected patients $(\mathrm{N}=8$, Supplementary Information 1).

Moreover, no significant correlations between IFIG expression levels at baseline (day_0) and VL decline from week_3 to week_6 or week_6 to week_12 could be detected in $23 \mathrm{HIV} / \mathrm{HCV}$ co-infected (HIV-aviremic) patients or in $8 \mathrm{HIV}$ mono-infected patients (data not shown).

Association between IFIG inductions ( $\Delta$ IFIG) with HIV declines from day_0 to week_3 in 8 HIV mono-infected patients

No significant correlation was detected between IFIG expression changes ( $\triangle$ IFIG) from day_0 to week_3 and median HIV-VL decline/ week from day_0 to week_3 (Table 1).

Association between IFIG inductions ( $\Delta$ IFIG: day_0 to week_48) with PegIFNa therapy outcome, i.e. sustained virologic response (SVR), in $23 \mathrm{HIV} / \mathrm{HCV}$ co-infected (HIVaviremic) patients

Given that IFIG expression was measured only at day_0 and week_48 in the $\mathrm{HIV} / \mathrm{HCV}$ co-infected cohort (in contrast to measurements in HIV mono-infected patients that were performed at day_0 and week_3, _6, _12 and _18) our means to associate IFIG induction ( $\triangle$ IFIG) with the primary endpoint of virologic response (=elimination of $\mathrm{HCV}$ ) were confined to checking for significant associations between IFIG induction from day_0 [21] to week_48 and SVR (=HCV-VL below limit of detection at week 72). Here, induction of Interferon stimulated exonuclease gene $20 \mathrm{kDa}(\Delta \mathrm{ISG} 20)$ showed a significant association $(\mathrm{P}<0.05)$ with SVR (using 1 -way-ANOVA and after accounting for False Discovery Rate, FDR).

\begin{tabular}{|c|c|c|}
\hline $\begin{array}{c}\text { IFIG } \\
(\Delta \text { Gene Symbol) }\end{array}$ & $\begin{array}{c}p \text { value } \\
\text { [day_0 to week_3] }\end{array}$ & $\begin{array}{c}p \text { value } \\
\text { [day_0 to week_12] }\end{array}$ \\
\hline$\Delta \mathrm{ISG} 20$ & $1,27 \mathrm{E}-01$ & $1,58 \mathrm{E}-01$ \\
\hline$\triangle \mathrm{APOBEC} 3 \mathrm{G}$ & $2,17 E-01$ & $2,21 \mathrm{E}-01$ \\
\hline$\triangle \mathrm{OAS} 1$ & $3,10 \mathrm{E}-01$ & $3,43 E-01$ \\
\hline$\Delta \mathrm{IRF} 7$ & 3,56E-01 & 3,79E-01 \\
\hline$\Delta \mathrm{IFIT1}$ & $4,06 \mathrm{E}-01$ & $4,23 E-01$ \\
\hline$\Delta$ ISG15 & $4,50 \mathrm{E}-01$ & $4,81 \mathrm{E}-01$ \\
\hline$\Delta \mathrm{G} 1 \mathrm{P} 3$ & $5,46 \mathrm{E}-01$ & 5,93E-01 \\
\hline$\triangle \mathrm{OAS} 2$ & $6,17 \mathrm{E}-01$ & $6,64 \mathrm{E}-01$ \\
\hline$\Delta \mathrm{MX} 2$ & $6,19 E-01$ & $6,82 \mathrm{E}-01$ \\
\hline$\Delta \mathrm{SP} 110$ & $6,75 E-01$ & $6,95 \mathrm{E}-01$ \\
\hline$\Delta$ LY6E & $6,79 E-01$ & $6,99 \mathrm{E}-01$ \\
\hline$\triangle$ STAT1 & $6,94 \mathrm{E}-01$ & $7,12 \mathrm{E}-01$ \\
\hline$\Delta \mathrm{MX} 1$ & $7,19 E-01$ & $7,48 \mathrm{E}-01$ \\
\hline$\Delta$ TRIM5 & 7,21E-01 & 7,97E-01 \\
\hline$\Delta \mathrm{IFIT3}$ & 7,43E-01 & 7,99E-01 \\
\hline$\triangle \mathrm{PLSCR} 1$ & 7,71E-01 & $8,21 \mathrm{E}-01$ \\
\hline$\Delta \mathrm{IFI} 44$ & $7,75 \mathrm{E}-01$ & $8,42 E-01$ \\
\hline$\Delta$ IFITM1 & $8,28 \mathrm{E}-01$ & 8,67E-01 \\
\hline$\triangle \mathrm{APOBEC} 3 \mathrm{~A}$ & 8,37E-01 & $8,78 \mathrm{E}-01$ \\
\hline$\triangle \mathrm{EIF} 2 \mathrm{AK} 2$ & $9,03 E-01$ & $9,36 \mathrm{E}-01$ \\
\hline$\Delta \mathrm{IFI} 27$ & $9,79 E-01$ & $9,92 \mathrm{E}-01$ \\
\hline
\end{tabular}

No significant association between IFIG induction and median HIV-VL declines/ week from day_0 to week_3 could be found in 8 HIV mono-infected patients receiving pegylated interferon alpha (PeglFNa) therapy. $\Delta$ is the mathematical symbol for induction. Gene Symbols correspond to Entrez Gene IDs (http://www. ncbi.nlm.nih.gov/gene). Of note, HIV viremia was still detectable in all HIV monoinfected donors at week_12; thus, the only pursuable aim regarding the role of IFIG induction in determining therapy outcome was here confined to examining correlations between IFIG expression changes and median HIV-VL decline/week from day 0 to week 12 . Of note, no significant correlations were found in this regard. No accounting for FDR was considered necessary in these contrast as results did not reach significance (i.e., $\mathrm{P}>0.05$ ).

Table 1: Association between Interferon inducible genes (IFIG) induction and Human Immunodeficiency Virus viral load (HIV-VL) declines.

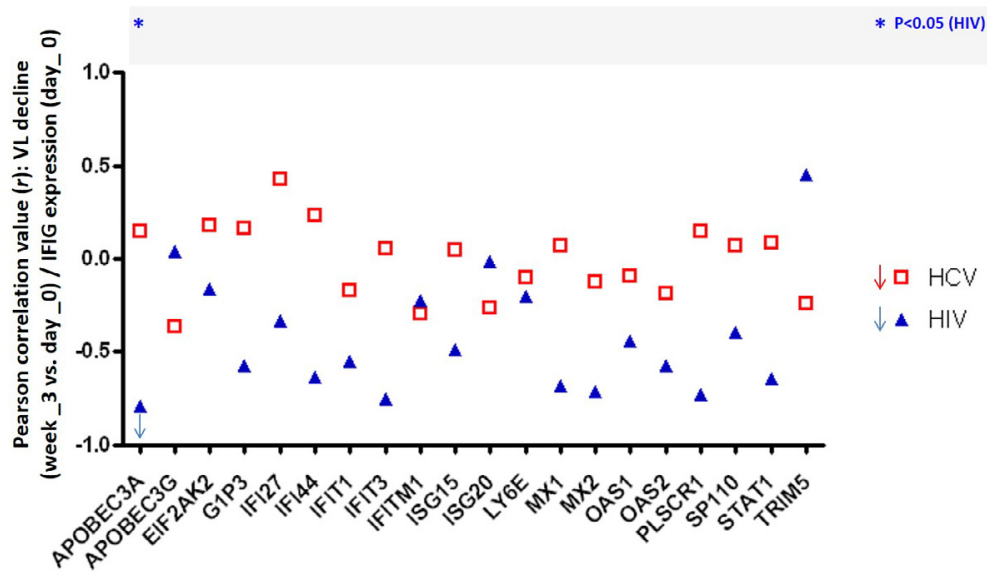

Figure 3: Correlation between Interferon inducible gene (IFIG) expression levels at baseline and viral load (VL) declines.

Differential association of interferon inducible gene (IFIG) expression levels at baseline (i.e. day 0) with Hepatitis C Virus (HCV)-VL or Human Immunodeficiency Virus (HIV)-VL median per week declines from day_0 to week 3 during pegylated interferon alpha (PegIFNa) therapy. Gene Symbols correspond to Entrez Gene IDs (http://www.ncbi.nlm.nih.gov/gene). 
Citation: Katsounas A, Frank AC, Lempicki RA, Polis MA, Asmuth DM, et al. (2015) Differential Specificity of Interferon-alpha Inducible Gene Expression in Association with Human Immunodeficiency Virus and Hepatitis C Virus Levels and Declines in vivo. J AIDS Clin Res 6: 410. doi:10.4172/2155-6113.1000410

\section{Discussion}

In this study, we demonstrated that distinct IFIG induction by exogenous interferon results in declines of HIV and HCV viral load in subjects receiving therapy. Although IFNa has been shown to have antiviral efficacy against both HIV and HCV replication [15,22], probably mediated through induction of IFIG, the specific role of individual IFIG against HIV and HCV has not yet been characterized. Here, we were able to dissect the clinical relevance of individual IFIG induced by PegIFNa in subjects infected with HIV and/or HCV. These findings will be helpful in further understanding IFNa mediated antiviral activity in vivo and allow us to make the use of interferon more specific and thus hopefully more efficient.

Despite the well-known capability of PegIFNa based therapy to inhibit HCV as well as HIV replication [15,22], the therapeutic outcome for HCV is eradication and for HIV is only long term suppression. To date, it remains unclear whether this is due to mechanisms devised by HIV to circumvent IFN signaling or due to inability of interferons to target HIV reservoirs in vivo. In this light, while the biological effects of interferons have long been recognized $[1,23,24]$, we were able to differentiate the patterns of the host IFIG expression in association with viral kinetics to demonstrate the specificity of IFN mediated anti-HCV and anti-HIV actions. Our results clearly support the importance of some genes, i.e., OAS1/2, MX1/2, APOBEC3A, APOBEC3G and ISG20 in the human antiviral defense, while also suggesting that these gene products likely exert different roles against HIV in comparison to HCV.

Previous research adds confidence to these results as for example APOBEC3A, which has been proven capable of mediating specific degradation of the nuclear viral DNA of the hepatitis B retrovirus [25], is also characterized by significant up-regulation in individuals with undetectable levels of HIV viremia in the absence of ART relative to infected (untreated) HIV patients [26]. In this regard, data from the present study further highlight the suggested antiretroviral role of APOBEC3A but also demonstrate a lack of induction for APOBEC3A gene expression in patients with high levels of HIV viremia receiving PegIFNa. Moreover, in line with previous work, we confirm that both IFIG up-regulation prior to therapy and inability to induce IFIG serve as strong negative predictors of SVR in patients with chronic HCV infection [16,27].

Furthermore, a significant association between SVR and ISG20 induction in vivo has been described here and elsewhere [21]; however, this study was unable to detect the same association between any IFIG expression/induction and HIV-VL drop. Hence, it is conceivable that PegIFNa induces a distinct antiviral response that specifically targets HCV, which leads to clearance of HCV. However, these IFIG, although induced in patients with HIV viremia, do not correlate with HIV suppression. This is perhaps, due to the inability of PegIFNa and its mediators of antiviral activity to effectively target HIV replication. Another explanation would be that HIV replication is refractory to the same IFIG that target and clear HCV from infected hepatocytes. In summary, our results suggest diverse pathways of IFIG induction by IFNa that lead to clearance of HCV, which may help us in understanding the inability of type I IFN to target HIV reservoirs in vivo.

This research has some limitations that warrant special attention. First, the fact that expression of some genes demonstrated correlations, which approached but did not reach statistical significance, should be considered in the light of the relatively small sample size of the present study especially of the HIV mono-infected patient group. Moreover, in this study, we neither examined the function of gene products nor the expression of the genes in other tissue compartments other than PBMC including the lack of liver sampling in HIV/HCV co-infected patients. However, in this regard, our previous studies have demonstrated a striking positive correlation between IFIG expression in the liver and PBMC in HIV/HCV co-infected subjects [28]. Furthermore, a number of genes (Tetherin, APOBEC3F, etc...) elsewhere identified as having influence on IFN-induced treatment outcome in HCV and HIV infection were not subject of investigation in this study [29,30]. Last but not least, it will be difficult to validate our findings in other HIVcohorts because PegIFNa is not used for treatment of HIV in standard clinical settings making it difficult to study large number of HIV monoinfected patients treated with IFN formulations. Ideally, a comparative group of HIV-negative healthy volunteers who received interferon may be necessary to weed out the intricate differential effects of ongoing HIV replication on IFN signaling. Moreover, measuring IFNa concentrations in plasma and correlating them with IFIG expression would also be ideal to draw more clear conclusions on IFIG expression/ induction. However, it has been shown that most patients have IFNa levels below the limit of detection and that type 2 and 3 interferon responses may be the ones that are driving high IFIG expression [31].

Taken together, this study provided first in vivo evidence that PegIFNa antiviral action is likely mediated by distinct IFIG in HIV and HCV infection. Understanding the gene expression differences and antiviral effects of IFN administration in HIV-infected patients is important, because IFN remains the only known curative treatment for chronic (retro-) viral illness [3], whereas current anti-HIV therapies alter the course of but cannot cure HIV. Elucidating mechanisms underlying IFN effects, therefore, could prove an important step forward in the eradication of many chronic viral infections.

In conclusion, our study is the first attempt to dissect the in vivo correlates of IFN signaling that are directly associated with anti-HIV or anti-HCV effects. The differential association found in IFIG expression with both HIV and HCV kinetics, suggests multiple, possibly nonoverlapping mechanisms (involving regulation of different IFIG) for antiviral effect against HCV and HIV. Further research is warranted in designing clinical strategies to optimize antiviral effects of IFN in HIV infected subjects (e.g. sequential therapy with ART) aimed at achieving a cure. Such an understanding could provide important insights into immune mechanisms crucial to curing HIV an important goal in the global fight against the continuing HIV pandemic.

\section{Acknowledgements}

This work was supported by the National Institutes of Health $(\mathrm{NIH})$ (grant 1U01-AI068636 to the ACTG; grant 1U01-AI068634 to the ACTG Statistical and Data Analysis Center; Immunology Support Laboratory grant 201IC001 to University of California-Davis; and the Intramural Research Program of the $\mathrm{NIH}$, National Institute of Allergy and Infectious Disease under Contract No. HHSN261200800001E). The authors of this Research Article have received publication approval for ACTG-related data from the Scientific Committee Chair / Affiliation A5192 after a rigorous review process by the ACTG review committee.

\section{References}

1. Samuel CE (2001) Antiviral actions of interferons. Clin Microbiol Rev 14: 778809

2. Herbeuval JP, Shearer GM (2007) HIV-1 immunopathogenesis: how good interferon turns bad. Clin Immunol 123: 121-128.

3. Yang PL, Althage A, Chung J, Maier H, Wieland S, et al. (2010) Immune effectors required for hepatitis B virus clearance. Proc Natl Acad Sci U S A 107: 798-802.

4. Manns MP, McHutchison JG, Gordon SC, Rustgi VK, Shiffman M, et al. (2001) Peginterferon alfa-2b plus ribavirin compared with interferon alfa- $2 b$ plus ribavirin for initial treatment of chronic hepatitis $\mathrm{C}$ : a randomised trial. Lancet 358: 958-965. 
Citation: Katsounas A, Frank AC, Lempicki RA, Polis MA, Asmuth DM, et al. (2015) Differential Specificity of Interferon-alpha Inducible Gene Expression in Association with Human Immunodeficiency Virus and Hepatitis C Virus Levels and Declines in vivo. J AIDS Clin Res 6: 410. doi:10.4172/2155-6113.1000410

5. Feld JJ, Hoofnagle JH (2005) Mechanism of action of interferon and ribavirin in treatment of hepatitis C. Nature 436: 967-972.

6. Yamamoto JK, Barré-Sinoussi F, Bolton V, Pedersen NC, Gardner MB (1986) Human alpha- and beta-interferon but not gamma- suppress the in vitro replication of LAV, HTLV-III, and ARV-2. J Interferon Res 6: 143-152.

7. Pincetic A, Kuang Z, Seo EJ, Leis J (2010) The interferon-induced gene ISG15 blocks retrovirus release from cells late in the budding process. J Virol 84: $4725-4736$.

8. Chen K, Huang J, Zhang C, Huang S, Nunnari G, et al. (2006) Alpha interferon potently enhances the anti-human immunodeficiency virus type 1 activity of APOBEC3G in resting primary CD4 T cells. J Virol 80: 7645-7657.

9. Peng G, Lei KJ, Jin W, Greenwell-Wild T, Wahl SM (2006) Induction of APOBEC3 family proteins, a defensive maneuver underlying interferoninduced anti-HIV-1 activity. J Exp Med 203: 41-46.

10. Imamichi T, Yang J, Huang DW, Brann TW, Fullmer BA, et al. (2008) IL-27, a novel anti-HIV cytokine, activates multiple interferon-inducible genes in macrophages. AIDS 22: 39-45.

11. Greenwell-Wild T, Vázquez N, Jin W, Rangel Z, Munson PJ, et al. (2009) Interleukin-27 inhibition of HIV-1 involves an intermediate induction of type I interferon. Blood 114: 1864-1874.

12. Chiu YL, Soros VB, Kreisberg JF, Stopak K, Yonemoto W, et al. (2005) Cellular APOBEC3G restricts HIV-1 infection in resting CD4+ T cells. Nature 435: 108114

13. Cheney IW, Lai VC, Zhong W, Brodhag T, Dempsey S, et al. (2002) Comparative analysis of anti-hepatitis $C$ virus activity and gene expression mediated by alpha, beta, and gamma interferons. J Virol 76: 11148-11154.

14. Neumann A, Polis M, Rozenberg L, Jackson J, Reitano K, et al. (2007) Differential antiviral effect of PEG-interferon-alpha-2b on HIV and HCV in the treatment of HIV/HCV co-infected patients. AIDS 21: 1855-1865.

15. Asmuth DM, Murphy RL, Rosenkranz SL, Lertora JJ, Kottilil S, et al. (2010) Safety, tolerability, and mechanisms of antiretroviral activity of pegylated interferon Alfa-2a in HIV-1-monoinfected participants: a phase II clinical trial. J Infect Dis 201: 1686-1696.

16. Lempicki RA, Polis MA, Yang J, McLaughlin M, Koratich C, et al. (2006) Gene expression profiles in hepatitis $\mathrm{C}$ virus (HCV) and HIV coinfection: class prediction analyses before treatment predict the outcome of anti-HCV therapy among HIV-coinfected persons. J Infect Dis 193: 1172-1177.

17. Kottilil S, Yan MY, Reitano KN, Zhang X, Lempicki R, et al. (2009) Human immunodeficiency virus and hepatitis $\mathrm{C}$ infections induce distinct immunologic imprints in peripheral mononuclear cells. Hepatology 50: 34-45.
18. Benjamini Y, Hochberg $Y$ (1995) Controlling the False Discovery Rate: a practical and powerful approach to multiple testing. Journal of the Royal Statistical Society. Series B (Methodological) 57: 289-300.

19. Benjamini Y, Krieger A, Yekutieli D (2006) Adaptive linear step-up procedures that control the False Discovery Rate. Biometrika 93: 491-507.

20. Benjamini $Y$, Hochberg $Y$ (2000) On the adaptive control of the False Discovery Rate in multiple testing with independent statistics. Journal of Educational and Behavioral Statistics 25: 60-83

21. Katsounas A, Rasimas JJ, Schlaak JF, Lempicki RA, Rosenstein DL, et al. (2015) Interferon stimulated exonuclease gene $20 \mathrm{kDa}$ links psychiatric events to distinct hepatitis $C$ virus responses in human immunodeficiency virus positive patients. J Med Virol 86: 1323-1331.

22. Avidan NU, Goldstein D, Rozenberg L, McLaughlin M, Ferenci P, et al. (2009) Hepatitis $C$ viral kinetics during treatment with peg IFN-alpha-2b in HIV/HCV coinfected patients as a function of baseline CD4+ T-cell counts. J Acquir Immune Defic Syndr 52: 452-458.

23. Isaacs A, Lindenmann J (1957) Virus interference. I. The interferon. Proc R Soc Lond B Biol Sci 147: 258-267.

24. Isaacs A, Lindenmann J, Valentine RC (1957) Virus interference. II. Some properties of interferon. Proc R Soc Lond B Biol Sci 147: 268-273.

25. Lucifora J, Xia Y, Reisinger F, Zhang K, Stadler D, et al. (2015) Specific and nonhepatotoxic degradation of nuclear hepatitis B virus cccDNA. Science 343 1221-1228.

26. Abdel-Mohsen M, Raposo RA, Deng X, Li M, Liegler T, et al. (2013) Expression profile of host restriction factors in HIV-1 elite controllers. Retrovirology 10: 106

27. Hubbard JJ, Greenwell-Wild T, Barrett L, Yang J, Lempicki RA, et al. (2012) Host gene expression changes correlating with anti-HIV-1 effects in human subjects after treatment with peginterferon Alfa-2a. J Infect Dis 205: 1443-1447.

28. Katsounas A, Hubbard JJ, Wang CH, Zhang X, Dou D, et al. (2013) High interferon-stimulated gene ISG-15 expression affects HCV treatment outcome in patients co-infected with HIV and HCV. J Med Virol 85: 959-963.

29. Neil SJ, Zang T, Bieniasz PD (2008) Tetherin inhibits retrovirus release and is antagonized by HIV-1 Vpu. Nature 451: 425-430

30. Liddament MT, Brown WL, Schumacher AJ, Harris RS (2004) APOBEC3F properties and hypermutation preferences indicate activity against HIV-1 in vivo. Curr Biol 14: 1385-1391.

31. Meissner EG, Wu D, Osinusi A, Bon D, Virtaneva K, et al. (2015) Endogenous intrahepatic IFNs and association with IFN-free HCV treatment outcome. J Clin Invest 124: 3352-3363. 